Research Article

\title{
Synthesis of sludge-derived biochar modified with eggshell waste for monoethylene glycol removal from aqueous solutions
}

\author{
Andy G. Kumi ${ }^{1} \cdot$ Mona G. Ibrahim ${ }^{1,2} \cdot$ Manabu Fujii $^{3} \cdot$ Mahmoud Nasr $^{1,4}$ \\ Received: 4 July 2020 / Accepted: 8 September 2020 / Published online: 13 September 2020 \\ (c) Springer Nature Switzerland AG 2020
}

\begin{abstract}
In this study, the pyrolysis of sewage sludge was employed to prepare a biochar (BC) adsorbent that was modified using eggshell wastes, obtaining eggshell-modified biochar (EMBC). The adsorbent material was used for the removal of monoethylene glycol (MEG) from aqueous solutions under various adsorption conditions. Results showed that the specific surface area of EMBC (i.e., $3.95 \mathrm{~m}^{2} / \mathrm{g}$ ) was approximately twofold higher than that of $\mathrm{BC}$, implying that the application of eggshell waste would improve the surface adsorption performance. The optimum adsorption $\mathrm{pH}$ value was 7, achieving MEG removal efficiencies of $29.9 \%$ for $B C$ and $89.9 \%$ for EMBC using adsorbent dosage $=2 \mathrm{~g} / \mathrm{L}$, initial MEG concentration $=100 \mathrm{mg} / \mathrm{L}$, and $25^{\circ} \mathrm{C}$ within $60 \mathrm{~min}$. The adsorption mechanisms were illustrated regarding XRD, FTIR, and SEM, demonstrating that surface adsorption, pore-filling, precipitation, and complexation contributed to the adsorption process. The adsorption data fitted well to the Langmuir isotherm model with the maximum monolayer adsorption capacity of $12.20 \mathrm{mg} / \mathrm{g}$, implying a reversible physisorption mechanism. Based on a techno-economic feasibility assessment, the preparation of $B C$ and EMBC adsorbents for the treatment of $1 \mathrm{~m}^{3}$ of wastewater-containing ethylene glycol would require capital costs of 4.80 and 6.50 US\$, respectively. The selling of adsorbents and the economic benefit of tertiary treated water showed adequate annual profitability with payback periods of 12.97 and 6.79 years for the BC and EMBC scenarios, respectively. Hence, the study succeeded in preparing efficient and low-cost adsorbents that could be used for the tertiary treatment of petrochemical industrial wastewater containing toxic environmental pollutants.
\end{abstract}

Andy G. Kumi, kumi.andy@ejust.edu.eg| ${ }^{1}$ Environmental Engineering Department, Egypt-Japan University of Science and Technology, Alexandria, Egypt. ' 2 Environmental Health Department, High Institute of Public Health, Alexandria University, Alexandria, Egypt. ${ }^{3}$ Department of Civil and Environmental Engineering, Tokyo Institute of Technology, Tokyo, Japan. ${ }^{4}$ Sanitary Engineering Department, Faculty of Engineering, Alexandria University, Alexandria 21544, Egypt. 


\section{Graphic abstract}

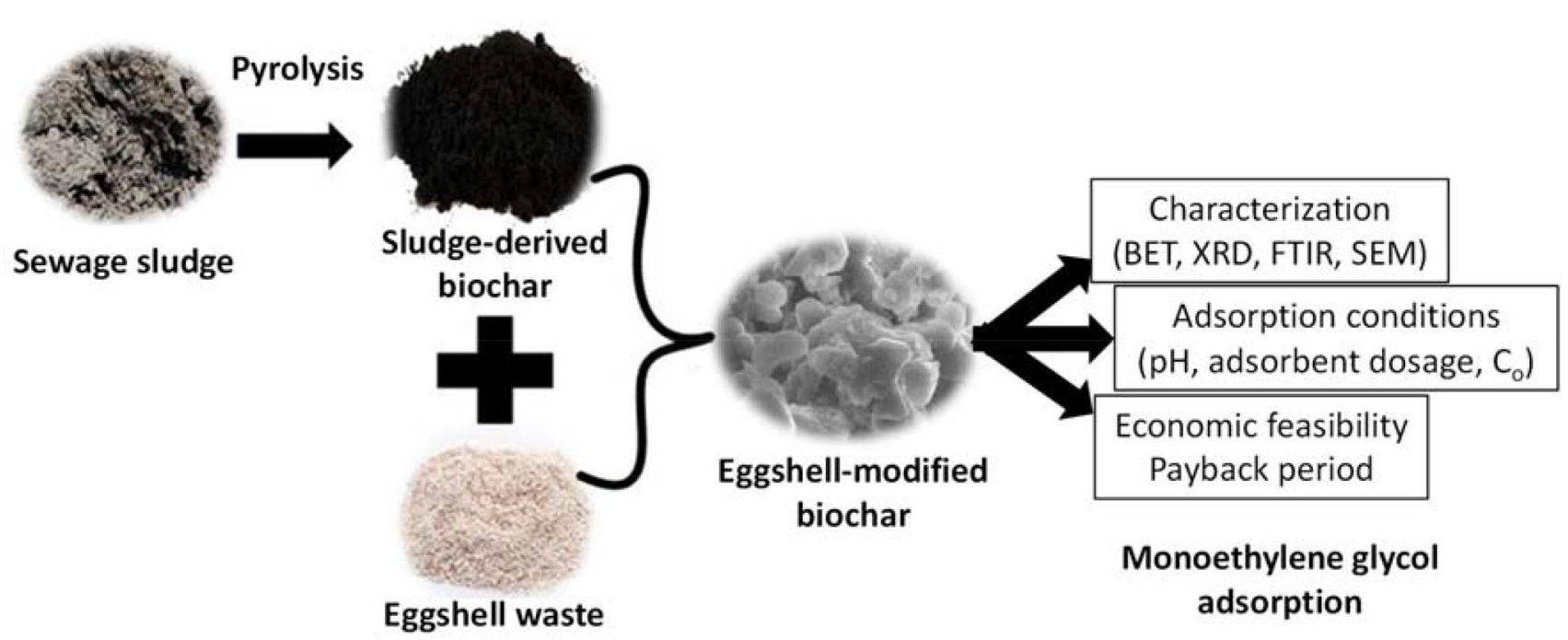

Keywords Adsorption conditions · Biochar-based sludge · Economic feasibility - Ethylene-glycol removal . Petrochemical wastewater

\section{Introduction}

Petrochemicals are large and complex chemical products derived from natural gas and petroleum, releasing monoethylene glycol (MEG) to the natural environment (e.g., water bodies) [1]. Monoethylene glycol (MEG; formula $\mathrm{HO}-\mathrm{CH}_{2}-\mathrm{CH}_{2}-\mathrm{OH}$ ) is an essential chemical product used to manufacture polyester fiber, bottles, and film [2]. It is also required to reduce the risk of gas hydrate formation during hydrocarbon transportation [3]. Petrochemical industrial wastewater laden with MEG is characterized by poor biodegradability, high toxicity, and carcinogenicity [4]. In addition, petrochemical effluents pose serious threats to human health, including damages of the brain, eyes, kidneys, and nervous system; or even death at high doses [5]. They also tend to deteriorate the environment and ecosystems; hence, removing MEG from the aquatic environment is of great importance.

Previous studies have attempted to eliminate MEG from aqueous solutions via the adsorption process using activated carbon [6, 7] and Zr-metal organic frameworks [5]. These studies have revealed that adsorption would be a promising and cost-effective approach for the treatment of wastewater containing MEG. Adsorption is a simple and environmentally friendly technology that has found relevant results, regarding energy utilization, sludge disposal issues, and operation and maintenance costs $[8,9]$.
In comparison, the biological systems used for the treatment of industrial wastewater containing ethylene glycol entail a retention time over $12 \mathrm{~h} \mathrm{[10].} \mathrm{The} \mathrm{long} \mathrm{hydraulic}$ residence time leads to large reactor volumes and initial investment costs [8]. Moreover, the chemical treatment of petroleum wastewater requires advanced reactions and processes, and it utilizes large amounts of reagent and raw material [3]. Furthermore, the membrane technology suffers from high energy consumption, fouling and scaling problems, and complex production and control procedures [11].

The selection of a low-cost, effective, and abundant adsorbent is an essential step in the adsorption technology $[12,13]$. In Egypt, huge quantities of sewage sludge are generated from wastewater treatment plants (WWTPs), releasing toxic substances into soil and groundwater. However, the sludge material could be appropriately utilized via the production of biochar as a carbon-rich adsorbent for the purpose of petrochemical wastewater treatment [14]. However, sludge-derived biochar might retain insufficient surface area and poor porosity after the pyrolysis process, reducing its practical application in the adsorption system [15]. In this context, the modification of biochar surface properties is an essential step to improve its adsorption capacity. Food wastes such as eggshells have been reported to contain a series of functional groups, intrinsic pore structure, and a mineral phase (calcite) that could improve the uptake capability of raw adsorbents 
[16]. Hence, the use of eggshell waste to modify the biochar surface properties for pollutant adsorption would be an attractive and interesting research topic.

The review articles by Liu et al. [17] and Xiang et al. [18] have summarized the recent applications of biochar as a low-cost, highly efficient, and eco-friendly adsorbent for the removal of a wide range of pollutants from industrial, agricultural, and municipal wastewaters. However, these comprehensive reviews demonstrate that few studies have focused on applying biochar for the removal of petroleum pollutants, suggesting that this topic has a knowledge gap in the existing literature. Hence, this study aimed at synthesizing a biochar material from sewage sludge, namely raw biochar (BC). Eggshell wastes were used to obtain eggshell-modified biochar (EMBC), which was applied as an adsorbent material for removing MEG from aqueous solutions. The adsorbent phase was characterized by Brunauer, Emmett and Teller (BET) specific surface area, Barrett-Joyner-Halenda (BJH) pore-size distribution, X-ray powder diffraction (XRD), Fourier-transform infrared (FTIR) spectroscopy, and scanning electron microscope (SEM). Moreover, the effects of adsorption conditions, i.e., solution $\mathrm{pH}$, adsorbent dosage, and initial MEG concentration $\left(C_{0}\right)$, on the MEG removal efficiency $(R)$ were investigated. The adsorption mechanisms were illustrated regarding isotherm studies (Langmuir and Freundlich models). Environmental consideration and economic feasibility for synthesizing the biochar adsorbents (BC and $E M B C$ ) to treat wastewater-containing ethylene glycol were determined.

\section{Materials and methods}

\subsection{Preparation of adsorbate (i.e., monoethylene glycol)}

An adsorbate solution (stock) with a concentration of $1000 \mathrm{mg} / \mathrm{L}$ was prepared using an analytical-reagent grade of MEG $\left(\mathrm{C}_{2} \mathrm{H}_{6} \mathrm{O}_{2}\right)$. The stock solution was diluted to prepare a series of MEG concentrations $(25,50,75,100,125$, and $150 \mathrm{mg} / \mathrm{L}$ ), as reported by Zaboon et al. [5]. The $\mathrm{pH}$ values of the MEG phase were adjusted using $0.1 \mathrm{M}$ solutions of either $\mathrm{HCl}$ or $\mathrm{NaOH}$. Distilled water was used throughout the study, and all chemicals were of analytical-reagent grade.

\subsection{Preparation of adsorbent (i.e., biochar and eggshell-modified biochar)}

Sewage sludge was collected from a full-scale municipal WWTP located at Alexandria Governorate. The obtained sludge samples were dried in an oven at $100^{\circ} \mathrm{C}$ for $24 \mathrm{~h}$, and then screened with standard sieves ( 60 mesh sieve) to obtain particle-diameters with a range of $0.25-0.50 \mathrm{~mm}$. The raw biochar $(\mathrm{BC})$ material was prepared by the pyrolysis of sewage sludge using a muffle furnace (Asahi Rika tabletop, AMF-25 N, Japan). An oxygen-free condition was enabled by vacuum evacuation for about $5 \mathrm{~min}$, and the pyrolysis process was performed at $900{ }^{\circ} \mathrm{C}$ with a heating rate of $5^{\circ} \mathrm{C} / \mathrm{min}$ for $60 \mathrm{~min}[17,19,20]$.

For the preparation of modified biochar, chicken eggshell waste was acquired from a restaurant at EgyptJapan University of Science and Technology (E-JUST). The collected eggshells were thoroughly washed and rinsed with distilled water several times to remove any impurities before drying in an oven at $100{ }^{\circ} \mathrm{C}$ for $24 \mathrm{~h}$. The dried chicken eggshells were crushed and grounded into fine powders using a stainless-steel grinder (Tornado steel grinder, MX 900/2, Egypt), and then subjected to $0.25-0.50 \mathrm{~mm}$ sieving. Finally, the eggshell-modified biochar (EMBC) was prepared by mixing the raw biochar with crushed eggshell waste with a ratio of 1:1 using a shaker (Benchmark, Incu-shaker mini, USA) [16].

\subsection{Adsorption experiment}

Batch adsorption experiments were conducted in $250-\mathrm{mL}$ flasks at a stirring rate of $100 \mathrm{rpm}$ and $25 \pm 2{ }^{\circ} \mathrm{C}$. A onefactor-at-a-time statistical method was used to study the influences of operational conditions on removing MEG from aqueous solutions within $60 \mathrm{~min}$. In the first experiment, the solution $\mathrm{pH}$ was adjusted between 2 and 10 at adsorbent dosage $=2 \mathrm{~g} / \mathrm{L}$, and $C_{0}=100 \mathrm{mg} / \mathrm{L}$. In the second experiment, the adsorbent dosage varied from 2 to $10 \mathrm{~g} / \mathrm{L}$ at the optimum $\mathrm{pH}$ (from the first test) and $C_{\mathrm{o}}=100 \mathrm{mg} / \mathrm{L}$. The third experiment was carried out by varying $C_{0}$ from 25 to $150 \mathrm{mg} / \mathrm{L}$ at the optimum $\mathrm{pH}$ and adsorbent dosage obtained from previous examinations. The adsorption data were used to estimate the MEG removal efficiencies (Eq. 1) and the adsorbents' uptake capacities (Eq. 2).

$R=\frac{C_{\mathrm{o}}-C_{\mathrm{e}}}{C_{\mathrm{o}}} \times 100$

$Q=\left(C_{\mathrm{o}}-C_{\mathrm{e}}\right) \times \frac{V}{m}$

where $R$ is the MEG removal efficiency (\%), $Q$ is the uptake capacity $(\mathrm{mg} / \mathrm{g}), \mathrm{m}$ the is biochar mass $(\mathrm{g}), V$ is the solution volume (L), and $C_{\mathrm{o}}$ and $C_{\mathrm{e}}$ are the initial and equilibrium concentrations of MEG, respectively ( $\mathrm{mg} / \mathrm{L})$.

\subsection{Analytical analysis}

For the determination of MEG concentrations, the solution was treated using a $0.22 \mu \mathrm{m}$ filter and analyzed by 
Gas Chromatography-Mass Spectrometry (Shimadzu Model GCMS-QP2010, Kyoto, Japan). The surface area and pore-size distribution of adsorbents were estimated using the Brunauer-Emmett-Teller (BET) and the Barrett-Joyner-Halenda (BJH) theories, respectively, (Bel Japan Inc., Belsorp mini-II) by recording the amount of liquid $\mathrm{N}_{2}$ adsorption on the biochar surface at $77 \mathrm{~K}$ [21]. The crystallinity of samples was investigated by an X-ray diffractometer (XRD) (Shimadzu Xlab 6100, Kyoto, Japan), operating at $40 \mathrm{kV}$ and $30 \mathrm{~mA}$ with Cu Ka radiation $(\lambda=1.5406 \AA)$. For XRD patterns, scans were taken over a $2 \theta$ range of $10^{\circ}-80^{\circ}$ with a step size of $0.02^{\circ}$ and a scan rate of $12^{\circ} \mathrm{C} / \mathrm{min}$. A Fourier Transform Infrared (FTIR) Spectroscopy (Bruker Vertex 70 Optics, Ettlingen, Germany) was used to record the variation of surface functional groups before and after adsorption over the 4000-400 $1 / \mathrm{cm}$ region. A scanning electron microscopy (SEM JEOL
JSM-6010LV JEOL, Tokyo, Japan) was used to display the surface morphology of adsorbents.

\section{Results and discussion}

\subsection{Biochar characterization}

Figure 1 shows the BET surface area characterization (Fig. 1a) and pore-size distribution (Fig. 1b) determined by the $\mathrm{N}_{2}$ adsorption/desorption tests. The EMBC adsorbent attained a twofold increase in the specific BET surface area compared to the case of BC. A similar pattern was observed for the total pore volume, implying the contribution of eggshells to modify the adsorbent surface [16]. The greater surface area would enhance MEG adsorption onto the respective adsorbent surface [20].


— EMBC before adsorption - - - - EMBC after adsorption

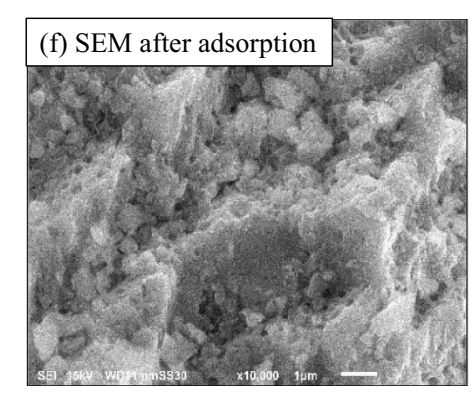

Fig. 1 Characterization of biochar (BC) and eggshell-modified biochar (EMBC) after adding eggshell wastes (EGS): a $\mathrm{N}_{2}$-adsorption isotherms for BET surface area calculation, b Bar-

rett-Joyner-Halenda $(B J H)$ pore size distribution, c XRD patterns of EMBC before and after adsorption, d FTIR spectra, e SEM micrograph before adsorption, and $\mathbf{f}$ SEM micrograph after adsorption 
The BET surface area for the prepared EMBC $\left(3.95 \mathrm{~m}^{2} / \mathrm{g}\right)$ was higher than that for rice-husk biochar of $0.63 \mathrm{~m}^{2} / \mathrm{g}$ [22], pine-wood biochar of $0.18 \mathrm{~m}^{2} / \mathrm{g}$ [23], and kelpmagnetic biochar of $0.97 \mathrm{~m}^{2} / \mathrm{g}$ [24]. The dominant pore size of eggshells was around $18 \mathrm{~nm}$ (Fig. 1b), suggesting almost a mesopores range $(2-50 \mathrm{~nm})$. In addition, the eggshells material exhibited a small peak in the microporosity region $(<2 \mathrm{~nm})$. The $B C$ material possessed various pore-size distribution peaks at the mesopores domain $(2-50 \mathrm{~nm})$, and hence, the synthesized EMBC adsorbent covered the micro-, meso- and macro-ranges. Results also demonstrated that the average pore sizes of $B C, E M B C$, and eggshells were $38.5 \mathrm{~nm}, 25.3 \mathrm{~nm}$, and $14.0 \mathrm{~nm}$, respectively.

Figure 1 also shows the phase identification of EMBC before and after MEG adsorption via the XRD analysis. Figure $1 \mathrm{c}$ depicts that the strongest diffraction peaks were assigned to $\mathrm{SiO}_{2}$ (quartz at $26.56^{\circ}$; PDF\#65-0466) and calcite $\left(\mathrm{CaCO}_{3}\right)$. The XRD patterns observed no other significant peaks, suggesting the amorphous carbon structure of the prepared biochar [22]. This result could also demonstrate that the EMBC particles were crystalline calcite, as calcite is the eggshell's major component [25].

Figure $1 \mathrm{~d}$ displays the FTIR spectra of the adsorbent material before and after MEG adsorption. It was demonstrated that the main functional groups of raw biochar were: $\mathrm{N}-\mathrm{H}$ stretching at $37001 / \mathrm{cm}$; bonded hydroxyl groups $(\mathrm{OH})$ at $3250-36001 / \mathrm{cm} ;-\mathrm{C}-\mathrm{H}$ or $\mathrm{CH}_{3}$ at $2100-23601 / \mathrm{cm} ;-\mathrm{CH}_{2}$ or aromatic $\mathrm{C}=\mathrm{C}$ stretching at 1417 1/cm; alcohol C-O stretching at $10291 / \mathrm{cm} ; \mathrm{C}-\mathrm{H}$ at 939 $1 / \mathrm{cm} ; \mathrm{Si}-\mathrm{O}$ at $4681 / \mathrm{cm}[8,12]$. These surface $\mathrm{OH}$ groups would serve as reactive sites for adsorbed species [26]. The shift of some bands after adsorption, e.g., $14171 / \mathrm{cm}$ was shifted to $14241 / \mathrm{cm}$ for $-\mathrm{CH}_{2}$ or $\mathrm{C}=\mathrm{C}$, implied the involvement of the relevant functional groups in the complexation of MEG. Similarly, Zaboon et al. [5] depicted that the variation of surface functional groups after MEG adsorption onto metal-organic frameworks could be attributed to (a) the presence of a trace of MEG bind with carbonyl carbons, and (b) the loading of a high amount of MEG inside the pores. Comparable bands were observed for the modified biochar (Fig. 1d); however, other functional groups were noted after the addition of eggshells, indicating the structure integrity [27]. For instance, the bands at 1636-1796 1/cm, $14111 / \mathrm{cm}$, and 708-873 1/cm could be assigned to carboxyl $\mathrm{C}=\mathrm{O}$, carbonate, and calcium carbonate, respectively, due to the eggshell component [28]. Based on these findings, the functional groups, namely alkane (e.g., $\mathrm{CH}_{2}$ and $\mathrm{CH}_{3}$ deformation), aromatic (e.g., $\mathrm{C}=\mathrm{C}$ stretching), alcohol (e.g., $\mathrm{O}-\mathrm{H}$ stretching, and $\mathrm{N}-\mathrm{H}$ stretching), and (e.g., ester S-OR stretching), located on the adsorbent surface could be beneficial to cause interactions and complexation with adsorbate pollutants.
The SEM micrographs in Fig. 1e-f show the morphology and porous structure of the investigated adsorbents at $10,000 \times$ magnification. Before adsorption, the adsorbent material had an active porous structure, with a smooth surface and vacant biochar pores (Fig. 1e). After the adsorption process (Fig. 1f), the biochar surface was dense, rough, and fully covered, indicating a pore-filling mechanism [29].

\subsection{Effect of solution pH}

Figure 2a shows the influence of solution $\mathrm{pH}$ on removing MEG by biochars (i.e., $B C$ and $E M B C$ ) at an adsorbent dosage of $2 \mathrm{~g} / \mathrm{L}, C_{\mathrm{o}}=100 \mathrm{mg} / \mathrm{L}$, and $60 \mathrm{~min}$. An increase in initial $\mathrm{pH}$ from 2 to 7 , respectively, caused an improvement of MEG removal from 22 to $30 \%$ for $B C(r 0.97 ; p 0.02)$ and from 81 to $90 \%$ for EMBC ( $r 0.89 ; p 0.11)$. Similar patterns were found for the adsorption capacities, achieving maximum values of 15 and $45 \mathrm{mg} / \mathrm{g}$ for $\mathrm{BC}$ and $\mathrm{EMBC}$, respectively, at $\mathrm{pH}$ about 7 . Further, an increase in $\mathrm{pH}$ over 7 caused a slight drop in the MEG removal efficiency. The influence of $\mathrm{pH}$ on the adsorption process could be explained by the point of zero charge $\left(\mathrm{pH}_{\mathrm{PZC}}\right)$ of the biochars shown in Fig. 2b. It was demonstrated that the net surface charge of the adsorbent approached zero at a solution $\mathrm{pH}$ of about 8.0 for $\mathrm{BC}$ and 8.2 for EMBC. In the acidic phase, where solution $\mathrm{pH}$ is lower than $\mathrm{pH}_{\mathrm{PZC}}$, the adsorbent surface would carry more positive charges (i.e., $\mathrm{H}^{+}$). On the other side, as the solution $\mathrm{pH}$ increased over $\mathrm{pH}_{\mathrm{PZC}}$, the number of negatively charged sites increased; hence, the negative charges tended to cover the biochar surface. These patterns would increase the repulsive forces among active sites (either positive sites at $\mathrm{pH}<\mathrm{pH}_{\mathrm{PZC}}$ or negative sites at $\mathrm{pH}>\mathrm{pH}_{\mathrm{PzC}}$ ), reducing the migration of MEG from the bulk solution to the surface of the adsorbent [30]. Overall, results indicated that the neutral condition favored the adsorption of MEG onto biochars; hence, $\mathrm{pH}=7$ was selected throughout this study. This finding complied with a previous work by Zaboon et al. [5], which demonstrated that neutral solutions $(\mathrm{pH}=7)$ provided the optimum condition for MEG removal via metal-organic frameworks.

\subsection{Effect of biochar dosage}

Figure $2 c$ shows the effect of biochar dosage on MEG's adsorption by $B C$ and $E M B C$ at a solution $\mathrm{pH}=7$, $C_{\mathrm{o}}=100 \mathrm{mg} / \mathrm{L}$, and $60 \mathrm{~min}$. An increase in dosage from 2 to $10 \mathrm{~g} / \mathrm{L}$, respectively, resulted in the improvement of the MEG removal efficiency from 29 to $49 \%$ for BC ( $r$ 0.99; $p<0.05)$ and from 90 to $96 \%$ for EMBC ( $r$ 0.98; 

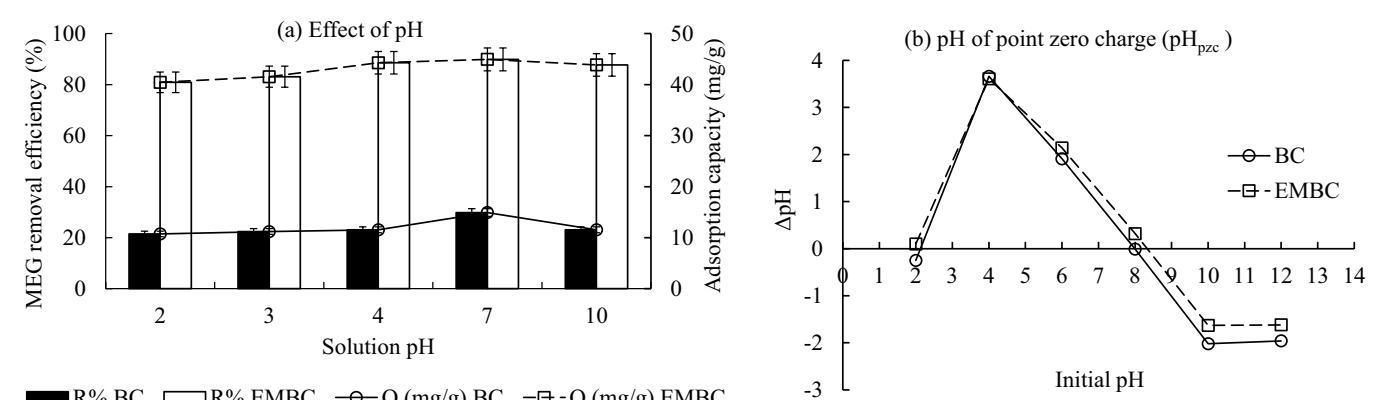

- $\mathrm{R} \% \mathrm{BC} \sqcup \mathrm{R} \% \mathrm{EMBC}-\mathrm{Q}(\mathrm{mg} / \mathrm{g}) \mathrm{BC} \quad-$ - $\mathrm{Q}(\mathrm{mg} / \mathrm{g}) \mathrm{EMBC}$
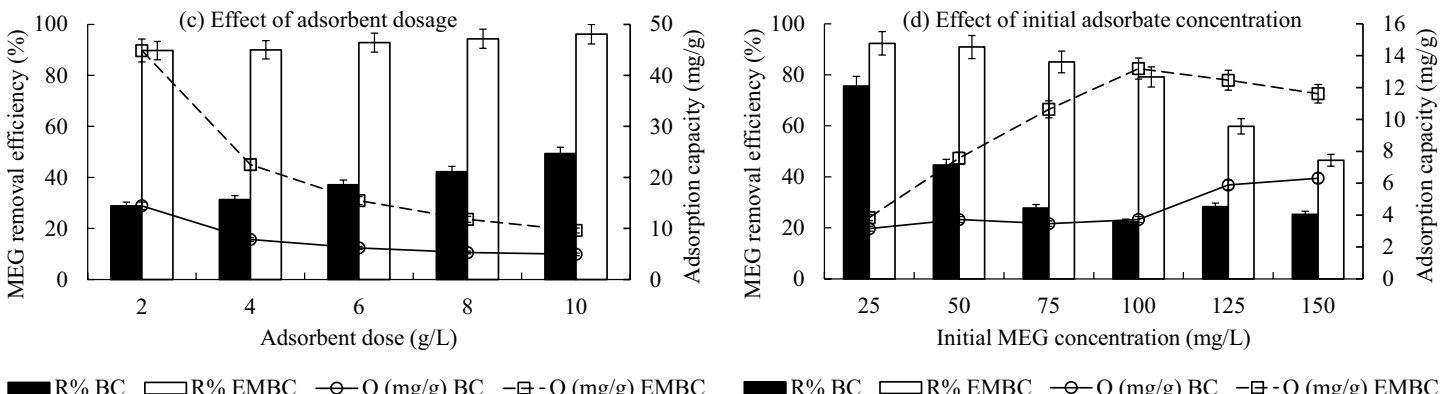

Fig. 2 Effects of experimental factors on adsorption of MEG onto biochar (BC) and eggshell-modified biochar (EMBC) at $25{ }^{\circ} \mathrm{C}$ within $60 \mathrm{~min}$ : a influence of solution $\mathrm{pH}(2-10 \mathrm{~g} / \mathrm{L})$ at adsorbent dosage $=2 \mathrm{~g} / \mathrm{L}$ and $C_{\mathrm{o}}=100 \mathrm{mg} / \mathrm{L}, \mathbf{b}$ variation of $\mathrm{pH}$ at point zero

$p<0.05)$. This result could be attributed to the increase in the number of available adsorption sites at higher doses [21]. On the contrary, the adsorption capacity observed a negative correlation with the adsorbent dose, which could be because some of the adsorption pores remained unoccupied during the adsorption process [31]. However, the increase in adsorbent dosage from 6 to $10 \mathrm{~g} / \mathrm{L}$ attained insignificant $(p>0.05)$ improvement in the adsorption system. Accordingly, a biochar dosage of $6 \mathrm{~g} / \mathrm{L}$ was chosen for further studies.

\subsection{Effect of initial MEG concentration $\left(C_{0}\right)$}

The effect of $C_{0}$ on the adsorption process was investigated at the optimum $\mathrm{pH}$ of 7 and biochar dosage of $6 \mathrm{~g} / \mathrm{L}$ within $60 \mathrm{~min}$ (Fig. 2d). An increase in $C_{0}$ caused a decline in the MEG's percentage removal, achieving the least values of $25.3 \%$ for $B C$ and $46.5 \%$ for EMBC at $C_{0} 150 \mathrm{mg} / \mathrm{L}$. This finding could be because the number of available adsorption sites became generally fully occupied with increasing the amount of adsorbate species (i.e., higher $C_{\mathrm{o}}$ ) [6]. On the contrary, the adsorption capacity increased at higher $C_{0}$ due to the enhanced driving force to overcome the resistance of MEG transfer from the solution medium to the surface of the biochar [23].

charge $\left(\mathrm{pH}_{\mathrm{PzC}}\right)$, c influence of adsorbent dosage at $\mathrm{pH}=7$ and $C_{\mathrm{o}}=100 \mathrm{mg} / \mathrm{L}$, and $\mathbf{d}$ influence of initial MEG concentration at $\mathrm{pH}=7$ and adsorbent dosage $=2 \mathrm{~g} / \mathrm{L}$

\subsection{Adsorption isotherm}

In this part, the Langmuir and Freundlich isotherm models were used to describe and quantify the adsorption of MEG onto biochars through various $C_{0}$ values under optimal conditions ( $\mathrm{pH} 7$, and dosage $6 \mathrm{~g} / \mathrm{L}$ ).

\subsubsection{Langmuir isotherm}

Langmuir isotherm is used to describe the adsorption mechanism under the equilibrium conditions, occurring over a homogeneous monolayer surface [32]. The constant parameters of the Langmuir model could be estimated by fitting the linear expression (Eq. 3) to the adsorption data.

$\frac{C_{\mathrm{e}}}{Q_{\mathrm{e}}}=\frac{1}{K_{\mathrm{L}} \times Q_{\mathrm{m}}}+\frac{C_{\mathrm{e}}}{Q_{\mathrm{m}}}$

where, $C_{e}(\mathrm{mg} / \mathrm{L})$ and $Q_{e}(\mathrm{mg} / \mathrm{g})$ are MEG concentration and amount of adsorbate uptake at equilibrium, respectively, and $Q_{\mathrm{m}}(\mathrm{mg} / \mathrm{g})$ and $K_{\mathrm{L}}(\mathrm{L} / \mathrm{mg})$ are the Langmuir constants that describe the maximum monolayer adsorption capacity of an adsorbent and the affinity between an adsorbent and adsorbate, respectively.

The plot of $C_{\mathrm{e}} / Q_{\mathrm{e}}$ versus $C_{\mathrm{e}}$ results in a linear correlation with an intercept of $1 /\left(K_{\mathrm{L}} \times Q_{\mathrm{m}}\right)$ and a slope $=1 / Q_{\mathrm{m}}$. 


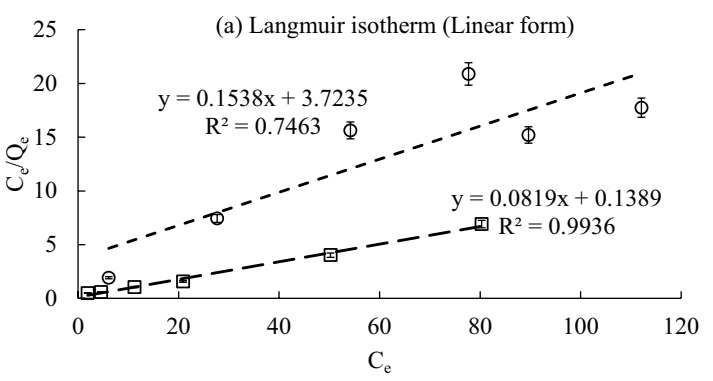

$\circ$ BC $\square$ EMBC - - - Linear $(\mathrm{BC})--$ Linear $(\mathrm{EMBC})$



○ Data BC — Langmuir fit BC ---Freundlich fit BC

Fig. 3 Isotherm study for adsorption of MEG onto biochar (BC) and eggshell-modified biochar (EMBC) within 60 min: a estimation of Langmuir model parameters, $\mathbf{b}$ estimation of Freundlich model

The plot in Fig. 3a depicted that the values of $Q_{\mathrm{m}}$ and $K_{\mathrm{L}}$ respectively, were $6.50 \mathrm{mg} / \mathrm{g}$ and $0.04 \mathrm{~L} / \mathrm{mg}$ for $B C$ and $12.20 \mathrm{mg} / \mathrm{g}$ and $0.59 \mathrm{~L} / \mathrm{mg}$ for EMBC. The higher $Q_{\mathrm{m}}$ and $K_{\mathrm{L}}$ values implied that $\mathrm{EMBC}$ attained better adsorption capabilities compared to BC [6].

The Langmuir constants were then used to estimate the separation factor $\left(R_{\mathrm{L}}\right)$, using Eq. (4) [33].

$R_{\mathrm{L}}=\frac{1}{1+K_{\mathrm{L}} \times C_{\mathrm{o}}}$

where $R_{\mathrm{L}}$ is an equilibrium parameter (dimensionless factor).

The shape of Langmuir isotherm is Irreversible at $R_{\mathrm{L}}=0$, Linear at $R_{\mathrm{L}}=1$, Unfavorable at $R_{\mathrm{L}}>1$, and Favorable at $R_{\mathrm{L}}<1$ [34]. In the present investigation, the $R_{\mathrm{L}}$ values were 0.13 for $B C$ and 0.01 for $E M B C$, suggesting that the adsorption of MEG onto biochars was favorable under the experimental conditions.

\subsubsection{Freundlich isotherm}

The Freundlich isotherm model is based on the assumption that adsorption occurs onto a heterogeneous surface of an adsorbent [35]. The linear form of Freundlich isotherm is expressed by Eq. (5).

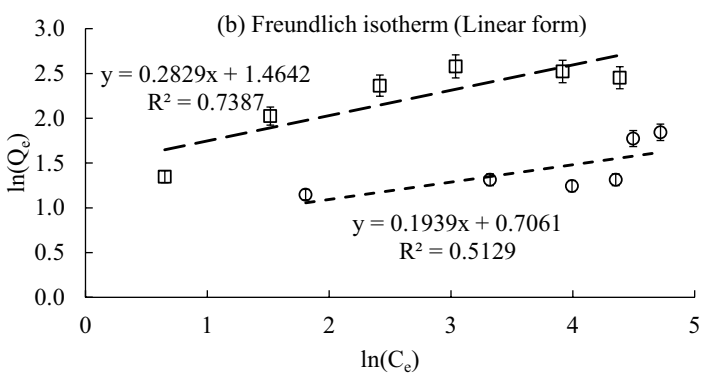

$\circ$ BC $\square$ EMBC - - - Linear $(\mathrm{BC})-$ - Linear (EMBC)

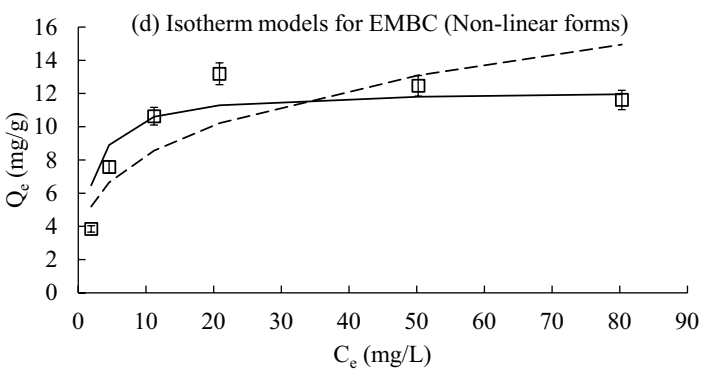

$\square$ Data EMBC — Langmuir fit EMBC - - - Freundlich fit EMBC

parameters, c fit of adsorption data for BC to Langmuir and Freundlich isotherm models, and $\mathbf{d}$ fit of adsorption data for EMBC to Langmuir and Freundlich isotherm models

$\ln \left(Q_{\mathrm{e}}\right)=\ln \left(K_{\mathrm{F}}\right)+\frac{1}{n} \ln \left(C_{\mathrm{e}}\right)$

where $K_{\mathrm{F}}$ represents the Freundlich adsorption capacity $(\mathrm{mg} / \mathrm{g}) /(\mathrm{mg} / \mathrm{L})^{n}$, and $\mathrm{n}$ is the Freundlich intensity constant related to the surface heterogeneity (dimensionless), in which, favorable adsorption occurs when the value of $n$ ranges between 0 and 10 [36].

The linear plot of $\ln \left(Q_{\mathrm{e}}\right)$ against $\ln \left(C_{\mathrm{e}}\right)$ caused a straight line with a slope and an intercept of $1 / n$ and $\ln \left(K_{\mathrm{F}}\right)$, respectively (Fig. 3b). These findings indicated that the Freundlich constants $\left(K_{\mathrm{F}}\right.$ and $\left.n\right)$ were derived as $2.03(\mathrm{mg} / \mathrm{g}) /$ $(\mathrm{mg} / \mathrm{L})^{n}$ and 5.16 for $\mathrm{BC}$ and $4.32(\mathrm{mg} / \mathrm{g}) /(\mathrm{mg} / \mathrm{L})^{n}$ and 3.53 for EMBC.

Based on the isotherm study (Fig. 3c, d), the nonlinearized Langmuir equation (Eq. 6) provided a better fit for the adsorption data, suggesting higher accuracy than the Freundlich model (Eq. 7).

$Q_{e}=Q_{m} \frac{K_{\mathrm{L}} \times C_{\mathrm{e}}}{1+K_{\mathrm{L}} \times C_{\mathrm{e}}}$

$Q_{\mathrm{e}}=K_{\mathrm{F}} \times C_{\mathrm{e}}^{1 / n}$

The outcomes of the isotherm study implied that MEG's adsorption onto both biochars (BC and EMBC) could be 
reversible and no interaction would occur among adsorbate species [34]. The $R_{\mathrm{L}}$ values obtained in this study complied with that found by Aworn et al. [7], using activated carbon synthesized from corncob to removal MEG $\left(R_{\mathrm{L}}\right.$ 0.076-0.156). In another study, Zaboon et al. [5] attained a higher $Q_{m}$ of $2000-2500 \mathrm{mg} / \mathrm{g}$ for the removal of MEG via $\mathrm{Zr}$-metal organic frameworks at $\mathrm{pH}=7$, which could be due to the use of different $C_{o}$ of $150-700 \mathrm{mg} / \mathrm{L}$ within $24 \mathrm{~h}$.

\subsection{Adsorption mechanism}

A recent review by Mohan et al. [37] has represented various applications of biochars for eliminating organics (e.g., dyes, antibiotics, pesticides, and phenolics) and inorganics (i.e., cations and anions). However, this review article lacks the removal of ethylene glycol from aqueous solutions. MEG $\left(\mathrm{HOC}_{2} \mathrm{H}_{4} \mathrm{OH}\right)$ molecules have a short-chain and nonelectrolyte adsorbate [38], and hence, they would be efficiently adsorbed on the whole surface of biochars. Accordingly, the adsorption mechanisms could be well described regarding the structure, morphology, and surface texture of the adsorbent, as well as the experimental conditions. The removal of MEG by biochars could occur due to the physical attachment of aqueous solution to the solid surface, involving weak van der Waals forces (i.e., Physisorption) [29]. Similarly, Aworn et al. [7] demonstrated that the removal mechanism of MEG onto corncob activated carbon was physisorption, with a saturation capacity of $4.51 \mathrm{~mol} / \mathrm{kg}$. The Van der Waals-London forces compress three main mechanisms, viz., (a) induced dipole-induced dipole interaction, (b) dipole-dipole interaction, and (c) dipole-induced dipole interaction [39]. The adsorption of MEG onto biochars also followed the Langmuir isotherm model with surface-monolayer interaction of $Q_{m}=12.20 \mathrm{mg} / \mathrm{g}$ (Fig. 3a), implying a reversible physisorption mechanism, as reported by Tran et al. [34]. In addition, no further interaction would occur between the adsorbent surface and MEG molecules when the biochar surface was saturated with a single-layer of the adsorbate molecules (monolayer adsorption). Likewise, Chang et al. [6] found that the adsorption of polyethylene glycol onto activated carbon followed the Langmuir isotherm model, describing the adsorption mechanism as surface and pore diffusions. Zaboon et al. [5] also depicted that Langmuir isotherm was the best model to fit the experimental data to remove MEG by $\mathrm{Zr}$-metal organic frameworks.

The physical properties of adsorbents (e.g., pore and surface structure) exhibited by BET results and SEM images (Fig. 1) revealed that precipitation or pore-filling would have largely contributed to MEG removal. Similarly, Fink [40] reported that ethylene glycol is a low-molecular compound that would be captured via physical adsorption and pore diffusion. This observation could also be attributed to the lack of strong functional groups for MEG that might contribute to a stronger bonding force with biochar. The shift of XRD peaks (i.e., mainly $\mathrm{CaCO}_{3}$ and $\mathrm{SiO}_{2}$ shown in Fig. 1c would imply the formation of some compounds such as MEG-carbonate complex $\left(\mathrm{HOC}_{2} \mathrm{H}_{4} \mathrm{OCO}_{2}{ }^{-}\right)$, as reported by Wang et al. [41].

In brief, we hypothesized that MEG removal by biochar might be attributed to surface adsorption, pore-filling, precipitation, and complexation; therefore, chemisorption of this compound onto biochar could be ruled out. The optimum condition of such an adsorption process could be specified at $\mathrm{pH}=7$. The eggshell-modified biochar was revealed to be a better adsorbent than raw sludge-derived biochar, which could be attributed to its enhanced porous structure with large surface area and numerous active sites.

\subsection{Environmental prospects and cost estimation}

This section represents the economic aspects associated with the adsorption of MEG onto biochar-based material, following the procedures reported by Mahmoud et al. [30] and Hamdy et al. [42]. The optimal experimental conditions $(\mathrm{pH}=7$, adsorbent dosage $=2 \mathrm{~g} / \mathrm{L}$, and adsorption time $=60 \mathrm{~min}$ at $25^{\circ} \mathrm{C}$ ), equivalent to the highest adsorption capacities, were used for the economic evaluation.

\subsubsection{Capital cost (CC)}

Capital cost (CC) was used to describe the sum of money spent on construction materials, equipment, tools, and installation, spreading over the project's lifetime. The lifespan was 10 years, with an annual interest rate of $8 \%$. CC was expressed as a cost per cubic meter of treated water $\left(\mathrm{US} \$ / \mathrm{m}^{3}\right)$. The construction cost was calculated from the capacity of the adsorption unit, as reported by Fawzy et al. [8] (Eq. 8).

$V=\frac{Q}{D} \times \frac{t_{\mathrm{r}}}{t_{\mathrm{w}}}$

where $V$ is the adsorption unit capacity $\left(\mathrm{m}^{3}\right), Q$ is the annual wastewater discharge $\left(\mathrm{m}^{3} /\right.$ year), $D$ is the working days (i.e., 336 days per year), $t_{\mathrm{r}}$ is the reaction time (i.e., $1 \mathrm{~h}$ ), $t_{\mathrm{w}}$ is the daily operating hours (i.e., $8 \mathrm{~h} /$ day).

The costs of construction and equipment were equivalent to about $28 \%$ and $45 \%$ of CC, respectively. The cost of the footprint (land expenses) represented 17\% of CC, whereas $5 \%$ of CC was distributed for wiring and piping. The summation of capital costs for the treatment of $1 \mathrm{~m}^{3}$ wastewater containing MEG was 4.80 US\$ for the BC option and 6.50 US\$ for the EMBC option. The equipment used for biochar preparation included an oven, standard sieves, muffle furnace (i.e., 
a rotary kiln would be considered for the pyrolysis process at a large-scale application), and a shaker. The higher CC of the EMBC case was due to the use of additional equipment such as a stainless-steel grinder and a shaker, requiring extra construction and footprint expenses. In another study, Hamdy et al. [42] found that the synthesis of zerovalent iron nanoparticles and its application for electroplating wastewater treatment would cost $4.45 \mathrm{US} \$ / \mathrm{m}^{3}$. Moreover, Nayunigari et al. [43] depicted that the total cost of scaling up the adsorption system (polyamine/folic acid composite as adsorbent) was 3.53 US\$ per $\mathrm{m}^{3}$ of wastewater containing $\mathrm{Cr}(\mathrm{VI})$. The variation in these costs could be associated with the local-currency pricing among countries used for assumptions; hence, the results in Table 1 were estimated with a precision of $\pm 15 \%$.

\subsubsection{Operating cost (OC)}

The operating cost $(\mathrm{OC})$ was expressed by the summation of prices used for reagents and chemicals, preparation of biochar-based sludge, energy consumption, and maintenance. For instance, the cost of chemicals (e.g., reagents) used for the adjustment of the solution's pH was calculated by Eq. (9).

$$
\text { Cost }_{\text {chemical }}=\sum\left(C_{i} \times P_{i}\right)
$$

where Cost $_{\text {chemical }}$ is the cost of all utilized reagents (US\$/ $\left.\mathrm{m}^{3}\right), C_{i}$ is the dose of each chemical $\left(\mathrm{g} / \mathrm{m}^{3}\right)$, and $P_{i}$ is cost

Table 1 Primary techno-economic estimation for preparation of biochar (BC) and eggshell-modified biochar (EMBC) adsorbents for treatment of $1 \mathrm{~m}^{3}$ of wastewater-containing ethylene glycol, with a precision of $\pm 15 \%$

\begin{tabular}{|c|c|c|c|}
\hline Item & $\mathrm{BC}$ & EMBC & Unit \\
\hline \multicolumn{4}{|c|}{ Item of initial investment in US\$/ $\mathrm{m}^{3}$} \\
\hline Construction & 1.34 & 1.82 & US\$ $/ \mathrm{m}^{3}$ \\
\hline Mechanical equipment & 2.16 & 2.93 & US\$ $/ \mathrm{m}^{3}$ \\
\hline Footprint & 0.82 & 1.11 & US\$ $/ \mathrm{m}^{3}$ \\
\hline Wiring and piping & 0.24 & 0.33 & US\$ $/ \mathrm{m}^{3}$ \\
\hline Others & 0.24 & 0.33 & US\$ $/ \mathrm{m}^{3}$ \\
\hline Capital cost & 4.80 & 6.50 & US\$ $/ \mathrm{m}^{3}$ \\
\hline \multicolumn{4}{|c|}{ Item of annual operation cost in US\$/ $\mathrm{m}^{3} /$ year } \\
\hline Chemical & 0.22 & 0.34 & US\$ $/ \mathrm{m}^{3} /$ year \\
\hline Adsorbent & 0.20 & 0.30 & US\$ $/ \mathrm{m}^{3} /$ year \\
\hline Energy & 0.34 & 0.53 & US\$ $/ \mathrm{m}^{3} /$ year \\
\hline Maintenance & 0.10 & 0.15 & US\$ $/ \mathrm{m}^{3} /$ year \\
\hline Running cost (US\$/ $/ \mathrm{m}^{3} /$ year) & 0.86 & 1.31 & US\$ $/ \mathrm{m}^{3} /$ year \\
\hline \multicolumn{4}{|l|}{ Profitability } \\
\hline Benefit-cost (USD/m³/year) & 1.23 & 2.27 & US\$ $/ \mathrm{m}^{3} /$ year \\
\hline Net profit (USD/m³/year) & 0.37 & 0.96 & US\$ $/ \mathrm{m}^{3} /$ year \\
\hline Payback period (years) & 12.97 & 6.79 & Years \\
\hline
\end{tabular}

for $1 \mathrm{~g}$ of a reagent (US\$/g; e.g., $0.1 \mathrm{US} \$$ for $1 \mathrm{~kg}$ of $\mathrm{NaOH}$ purchased from local chemical suppliers).

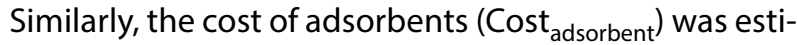
mated by Eq. (9), using 0.10 and 0.15 US\$/kg for BC and $E M B C$, respectively. The cost of energy (Cost energy ) was calculated from the amount of electricity consumed by the stirrer and pumps for scaling up the adsorption system. The electricity price was 0.10 US\$ per kWh, using the Egyptian tariff of 1.5 EGP/kWh ( 1 US\$ $=16.16$ EGP in June 2020). Labor cost was excluded in this economic assessment because adsorption is a relatively simple process that does not require extensive on-site monitoring or great experience. The maintenance cost ( Cost $\left._{\text {maintenance }}\right)$ was assumed as $2 \%$ of the annual investment cost, denoting the expenses necessary for equipment repair. The higher $O C$ for the EMBC preparation was attributed to additional activities (collection, transportation, and preparation) of the eggshell waste (Table 1).

\subsubsection{Environmental profitability}

As reported by Yunus et al. [44], the annual profitability of an adsorption system could be associated with selling the adsorbent material for the removal of toxic species. Based on information obtained from potential customers and suppliers, the marketing of EMBC could be $0.33 \mathrm{US} \$ \mathrm{~kg}$ compared to 0.15 US $\$ / \mathrm{kg}$ for BC. These expenses comply with the common adsorbent material, viz., 0.09-0.33 US\$/ $\mathrm{kg}$ for wood biochar, 0.60 US\$/kg for zeolite, and 1.50 US\$/ $\mathrm{kg}$ for activated carbon [21]. In addition, the adsorption system could be applied at a tertiary stage to avoid further environmental damages if contaminants are dumped in an unrestrained manner. The economic benefit of tertiary treated water by adsorption was assumed as $0.78 \mathrm{EGP}$ (i.e., 0.048 US\$) per cubic meter, equivalent to benefits from the reuse of the tertiary treated effluent [8]. Further, the adsorption system was economically assessed using the standard criterion of the payback period, as estimated from dividing capital cost by net profit. The payback period of the EMBC option (6.79 years) was shorter than the project lifetime (10 years), suggesting that the adsorption system by EMBC would gain financial profits in the long run. Moreover, the EMBC case attained a payback period shorter than the option of $B C$, implying that the use of modified biochar would require a faster length of time to compensate for the initial investment. The estimated payback period in this study was comparable to that found in a study by Fawzy et al. [8], showing that 5.7 years were suitable to earn back the initial investment for the adsorption of $\mathrm{Cd}^{2+}$ by agricultural wastes.

Based on the aforementioned data, the outcomes of this study are threefold: (1) environmental benefits via avoiding ecological damage from the release of toxic 
pollutants (e.g., MEG) into the ecosystem, (2) waste management via preventing the disposal of sewage sludge (e.g., preparation of biochar adsorbent), and (3) economic benefit (profit) via synthesizing novel adsorbent material having a twofold increase in the specific surface area compared to raw biochar.

Wang et al. [45] found that the combination of hydrothermal pretreatment with pyrolysis (HTP) would immobilize heavy metals in sewage sludge-derived biochar, as compared with the direct pyrolysis process. Their study also demonstrated that the increase in pyrolysis temperature could reduce the ecological risk associated with heavy metals in biochar prepared from the HTP process. Hence, the author's future study will focus on minimizing the potential risk of the heavy metals and toxic elements that could be found in the synthesized EMBC.

\section{Conclusions}

Monoethylene glycol (MEG) is an essential chemical product used in petrochemical industries; however, its presence in water bodies would cause severe environmental damages. Hence, this work aimed at preparing a low-cost and efficient adsorbent material for the removal of MEG pollutants from aqueous solutions. It was concluded that:

- Eggshell-modified biochar (EMBC) was adequately synthesized, attaining a higher surface area of $3.95 \mathrm{~m}^{2} / \mathrm{g}$ than raw biochar $(B C)$ of $2.15 \mathrm{~m}^{2} / \mathrm{g}$.

- At adsorbent dosage $=2 \mathrm{~g} / \mathrm{L}$ and $C_{\mathrm{o}}=100 \mathrm{mg} / \mathrm{L}$, the maximum MEG removal efficiencies using $B C$ and $E M B C$ were $29.9 \%$ and $89.9 \%$, respectively, under $25^{\circ} \mathrm{C}$ within $60 \mathrm{~min}$

- The adsorption data fitted well with the Langmuir isotherm model, achieving the maximum monolayer adsorption capacity of $12.20 \mathrm{mg} / \mathrm{g}$.

- Based on XRD, FTIR, and SEM examinations, the adsorption of MEG onto biochar adsorbents could be described as surface adsorption, pore-filling, precipitation, and complexation.

- The prepared biochar adsorbent would be used to treat wastewater-containing ethylene glycol, providing net profit values of 0.37 US\$ $/ \mathrm{m}^{3} /$ year for BC and 0.96 US\$/ $\mathrm{m}^{3} /$ year for EMBC.

- The payback period of the adsorption system by EMBC was shorter than the lifetime of the project (10 years), suggesting a profitability scenario.

- The EMBC case attained a payback period shorter than the option of $\mathrm{BC}$, implying that the use of modified biochar would require a faster length of time to recoup its initial investment.
- Further studies should be performed to reduce the health risks associated with heavy metals that could be found in EMBC, and estimate the capital and operational costs for large-scale adsorption processes.

Acknowledgements The first author would like to thank Egypt-Japan University of Science and Technology (E-JUST) and Japan International Cooperation Agency-JICA for providing all the facilities and equipment to accomplish this work.

Author contribution Andy G. Kumi: Methodology, Formal analysis, Writing —original draft; Mona G. Ibrahim: Conceptualization, Visualization, Writing—review \& editing; Manabu Fujii: Supervision, Visualization, Writing-review \& editing; Mahmoud Nasr: Conceptualization, Supervision, Writing-review \& editing.

\section{Compliance with ethical standards}

Conflict of interest The authors declare that they have no known competing financial interests or personal relationships that could have appeared to influence the work reported in this paper, including permission for sewage sludge and eggshell waste collections.

\section{References}

1. Bayat M, Mehrnia M, Hosseinzadeh M, Sheikh-Sofla R (2015) Petrochemical wastewater treatment and reuse by MBR: a pilot study for ethylene oxide/ethylene glycol and olefin units. J Ind Eng Chem 25:265-271. https://doi.org/10.1016/j. jiec.2014.11.003

2. Esmaeili A, Loghmani K (2016) Removal of monoethylene glycol from gas field wastewater using aspergillus tubingensis and a new bioreactor. Waste Biomass Valoriz 7(1):151-156. https://doi. org/10.1007/s12649-015-9430-z

3. Aljuboury D, Palaniandy P, Abdul Aziz H, Feroz S (2017) Treatment of petroleum wastewater by conventional and new technologies-a review. Glob Nest J 19(3):439-452. https://doi. org/10.30955/gnj.002239

4. Takht Ravanchi M, Kaghazchi T, Kargari A (2009) Application of membrane separation processes in petrochemical industry: a review. Desalination 235(1-3):199-244. https://doi. org/10.1016/j.desal.2007.10.042

5. Zaboon S, Abid H, Yao Z, Gubner R, Wang S, Barifcani A (2018) Removal of monoethylene glycol from wastewater by using Zr-metal organic frameworks. J Colloid Interface Sci 523:75-85. https://doi.org/10.1016/j.jcis.2018.03.084

6. Chang CF, Chang CY, Höll W, Ulmer M, Chen YH, Groß HJ (2004) Adsorption kinetics of polyethylene glycol from aqueous solution onto activated carbon. Water Res 38(10):2559-2570. https ://doi.org/10.1016/j.watres.2004.03.001

7. Aworn A, Thiravetyan P, Nakbanpote W (2009) Preparation of $\mathrm{CO}_{2}$ activated carbon from corncob for monoethylene glycol 
adsorption. Colloid Surf A Physicochem Eng Asp 333(1-3):1925. https://doi.org/10.1016/j.colsurfa.2008.09.021

8. Fawzy M, Nasr M, Abdel-Rahman A, Hosny G, Odhafa B (2019) Techno-economic and environmental approaches of $\mathrm{Cd}^{2+}$ adsorption by olive leaves (Olea europaea L.) waste. Int J Phytoremediation 21(12):1205-1214. https://doi. org/10.1080/15226514.2019.1612848

9. Islam M, Awual M, Angove M (2019) A review on nickel(II) adsorption in single and binary component systems and future path. J Environ Chem Eng 7(5):103305. https://doi. org/10.1016/j.jece.2019.103305

10. Hassani A, Borghei S, Samadyar H, Ghanbari B (2014) Utilization of moving bed biofilm reactor for industrial wastewater treatment containing ethylene glycol: kinetic and performance study. Environ Technol (UK) 35(4):499-507. https:// doi.org/10.1080/09593330.2013.834947

11. Van der Bruggen B, Mänttäri $M$, Nyström $M$ (2008) Drawbacks of applying nanofiltration and how to avoid them: a review. Sep Purif Technol 63(2):251-263. https://doi.org/10.1016/j. seppur.2008.05.010

12. Hamdy A, Mostafa M, Nasr M (2018) Zero-valent iron nanoparticles for methylene blue removal from aqueous solutions and textile wastewater treatment, with cost estimation. Water Sci Technol 78(2):367-378. https://doi.org/10.2166/wst.2018.306

13. Awual M (2019) A facile composite material for enhanced cadmium(II) ion capturing from wastewater. J Environ Chem Eng 7(5):103378. https://doi.org/10.1016/j.jece.2019.103378

14. Tan X, Liu Y, Zeng G, Wang X, Hu X, Gu Y, Yang Z (2015) Application of biochar for the removal of pollutants from aqueous solutions. Chemosphere 125:70-85. https://doi.org/10.1016/j. chemosphere.2014.12.058

15. Wang J, Wang S (2019) Preparation, modification and environmental application of biochar: a review. J Clean Prod 227:1002-1022. https://doi.org/10.1016/j.jclepro.2019.04.282

16. Carvalho J, Araujo J, Castro F (2011) Alternative low-cost adsorbent for water and wastewater decontamination derived from eggshell waste: an overview. Waste Biomass Valoriz 2(2):157-167. https://doi.org/10.1007/s12649-010-9058-y

17. Liu J, Jiang J, Meng Y, Aihemaiti A, Xu Y, Xiang H, Chen X (2020) Preparation, environmental application and prospect of biochar-supported metal nanoparticles: a review. J Hazard Mater 388:122026. https://doi.org/10.1016/j.jhazmat.2020.122026

18. Xiang W, Zhang X, Chen J, Zou W, He F, Hu X, Tsang D, Ok Y, Gao B (2020) Biochar technology in wastewater treatment: a critical review. Chemosphere 252:126539. https://doi. org/10.1016/j.chemosphere.2020.126539

19. Zhang J, Liu M, Yang T, Yang K, Wang H (2016) A novel magnetic biochar from sewage sludge: synthesis and its application for the removal of malachite green from wastewater. Water Sci Technol 74(8):1971-1979. https://doi.org/10.2166/ wst.2016.386

20. Kim JY, Oh S, Park YK (2020) Overview of biochar production from preservative-treated wood with detailed analysis of biochar characteristics, heavy metals behaviors, and their ecotoxicity. J Hazard Mater 384:121356. https://doi.org/10.1016/j.jhazm at.2019.121356

21. Shaheen S, Niazi N, Hassan N, Bibi I, Wang H, Tsang D, Rinklebe $J$ (2019) Wood-based biochar for the removal of potentially toxic elements in water and wastewater: a critical review. Int Mater Rev 64(4):216-247. https://doi.org/10.1080/09506 608.2018 .1473096

22. Shi J, Fan X, Tsang D, Wang F, Shen Z, Hou D, Alessi D (2019) Removal of lead by rice husk biochars produced at different temperatures and implications for their environmental utilizations. Chemosphere 235:825-831. https://doi.org/10.1016/j. chemosphere.2019.06.237
23. Lonappan L, Rouissi T, Kaur Brar S, Verma M, Surampalli R (2018) An insight into the adsorption of diclofenac on different biochars: mechanisms, surface chemistry, and thermodynamics. Bioresour Technol 249:386-394. https://doi.org/10.1016/j.biort ech.2017.10.039

24. Son EB, Poo KM, Chang JS, Chae KJ (2018) Heavy metal removal from aqueous solutions using engineered magnetic biochars derived from waste marine macro-algal biomass. Sci Total Environ 615:161-168. https://doi.org/10.1016/j.scito tenv.2017.09.171

25. Apalangya V, Rangari V, Tiimob B, Jeelani S, Samuel T (2014) Development of antimicrobial water filtration hybrid material from bio source calcium carbonate and silver nanoparticles. Appl Surf Sci 295:108-114. https://doi.org/10.1016/j.apsus c.2014.01.012

26. Awual M (2019) Novel ligand functionalized composite material for efficient copper(II) capturing from wastewater sample. Compos B Eng 172:387-396. https://doi.org/10.1016/j.compo sitesb.2019.05.103

27. Qin C, Wang H, Yuan X, Xiong T, Zhang J, Zhang J (2020) Understanding structure-performance correlation of biochar materials in environmental remediation and electrochemical devices. Chem Eng J 382:122977. https://doi.org/10.1016/j. cej.2019.122977

28. Giraldo L, Moreno-Piraján J (2014) Study of adsorption of phenol on activated carbons obtained from eggshells. J Anal Appl Pyrol 106:41-47. https://doi.org/10.1016/j.jaap.2013.12.007

29. Ben-Mansour R, Habib M, Bamidele O, Basha M, Qasem N, Peedikakkal A, Ali M (2016) Carbon capture by physical adsorption: materials, experimental investigations and numerical modeling and simulations-a review. Appl Energy 161:225-255. https:// doi.org/10.1016/j.apenergy.2015.10.011

30. Mahmoud A, Mostafa M, Nasr M (2019) Regression model, artificial intelligence, and cost estimation for phosphate adsorption using encapsulated nanoscale zero-valent iron. Sep Sci Technol (Philadelphia) 54(1):13-26. https://doi.org/10.1080/01496 395.2018.1504799

31. Pehlivan E, Arslan G (2007) Removal of metal ions using lignite in aqueous solution-low cost biosorbents. Fuel Process Technol 88(1):99-106. https://doi.org/10.1016/j.fuproc.2006.09.004

32. Langmuir I (1918) The adsorption of gases on plane surfaces of glass, mica and platinum. J Am Chem Soc 40(9):1361-1403. https://doi.org/10.1021/ja02242a004

33. Hall K, Eagleton L, Acrivos A, Vermeulen T (1966) Pore- and soliddiffusion kinetics in fixed-bed adsorption under constant-pattern conditions. Ind Eng Chem Fund 5(2):212-223. https://doi. org/10.1021/i160018a011

34. Tran H, You SJ, Hosseini-Bandegharaei A, Chao HP (2017) Mistakes and inconsistencies regarding adsorption of contaminants from aqueous solutions: a critical review. Water Res 120:88-116. https://doi.org/10.1016/j.watres.2017.04.014

35. Freundlich H (1906) Über die adsorption in Lösungen. Z Phys Chem 57:385-471. https://doi.org/10.1515/zpch-1907-5723

36. Kumar K (2006) Comments on "Adsorption of acid dye onto organobentonite. J Hazard Mater 137(1):638-639. https://doi. org/10.1016/j.jhazmat.2006.03.056

37. Mohan D, Sarswat A, Ok Y, Pittman C (2014) Organic and inorganic contaminants removal from water with biochar, a renewable, low cost and sustainable adsorbent-a critical review. Bioresour Technol 160:191-202. https://doi.org/10.1016/j.biort ech.2014.01.120

38. Tunç S, Duman O (2008) The effect of different molecular weight of poly(ethylene glycol) on the electrokinetic and rheological properties of Na-bentonite suspensions. Colloids Surf A Physicochem Eng Asp 317(1-3):93-99. https://doi.org/10.1016/j.colsu rfa.2007.09.039 
39. Banerjee $K$, Cheremisinoff $P$, Cheng $S$ (1995) Sorption of organic contaminants by fly ash in a single solute system. Environ Sci Technol 29(9):2243-2251. https://doi.org/10.1021/es00009a014

40. Fink J (2018) Reactive polymers: fundamentals and applications. A concise guide to industrial polymers. A volume in plastics design library, 3rd edn. Elsevier, Amsterdam

41. Wang P, Kosinski J, Anderko A, Springer R, Lencka M, Liu J (2013) Ethylene glycol and its mixtures with water and electrolytes: thermodynamic and transport properties. Ind Eng Chem Res 52(45):15968-15987. https://doi.org/10.1021/ie4019353

42. Hamdy A, Mostafa M, Nasr M (2019) Techno-economic estimation of electroplating wastewater treatment using zero-valent iron nanoparticles: batch optimization, continuous feed, and scaling up studies. Environ Sci Pollut Res 26(24):25372-25385. https://doi.org/10.1007/s11356-019-05850-3

43. Nayunigari M, Gupta S, Nasr M, Andaluri G, Suri R, Maity A (2019) Artificial neural network and cost estimation for $\mathrm{Cr}(\mathrm{VI})$ removal using polycationic composite adsorbent. Water Environ J. https ://doi.org/10.1111/wej.12501
44. Yunus Z, Al-Gheethi A, Othman N, Hamdan R, Ruslan N (2020) Removal of heavy metals from mining effluents in tile and electroplating industries using honeydew peel activated carbon: a microstructure and techno-economic analysis. J Clean Prod 251:119738. https://doi.org/10.1016/j.jclepro.2019.119738

45. Wang X, Chi Q, Liu X, Wang Y (2019) Influence of pyrolysis temperature on characteristics and environmental risk of heavy metals in pyrolyzed biochar made from hydrothermally treated sewage sludge. Chemosphere 216:698-706. https://doi. org/10.1016/j.chemosphere.2018.10.189

Publisher's Note Springer Nature remains neutral with regard to jurisdictional claims in published maps and institutional affiliations. 